\title{
The Effects of Psychology on Individual Investors' Behaviors: Evidence from the Vietnam Stock Exchange
}

\author{
Hoang Thanh Hue Ton ${ }^{1} \&$ Trung Kien $\mathrm{Dao}^{2}$ \\ ${ }^{1}$ School of Management, Shanghai University, Shanghai 200444, China \\ ${ }^{2}$ School of Economics and Management, Hanoi University of Science and Technology, Hanoi, Viet Nam \\ Correspondence: Hoang Thanh Hue Ton, School of Management, Shanghai University, Shanghai 200444, China. \\ E-mail: ththue14@gmail.com
}

Received: July 17, $2014 \quad$ Accepted: August 8, $2014 \quad$ Online Published: August 29, 2014

doi:10.5539/jms.v4n3p125

URL: http://dx.doi.org/10.5539/jms.v4n3p125

\begin{abstract}
This paper uses the theory of behavioral finance to examine the factors of individual investors' psychology as well as their effects on investment decisions in the Vietnam Stock Exchange (VSE). This is an empirical study which based on a survey of 422 investors. All of them have had the deep knowledge about finance investment and worked many years in VSE. The final results show that five factors of psychology which are overconfidence, optimism, herd behavior, psychology of risk and pessimistic have influence on investment decisions. To be more detailed, excessive optimism, psychology of risk and excessive pessimistic affect positively on long-term investment of investors while overconfidence and herd behavior have the negative impact. Based on the theory of behavioral finance, this study explains factors of individual investors' psychology. However, one of the limited of this paper is that it does not mention about negative outcomes of psychology factors on investment decisions. This is considered as a new path to do research in the future for emerging markets like Vietnam.
\end{abstract}

Keywords: behavioral finance, stock market, overconfidence, optimism, herd behavior, psychology of risk and pessimistic

\section{Introduction}

It should be noted that stock market is similar to humans' emotions because it also experiences the different feelings from sensitivity to ignorance. There are various factors affecting stock market. Apart from macro economics as well as the profitability of listed companies, psychology plays a crucial role. Psychology can not only boost the market fastly but also make it decrease deeply.

After 13 years of operation since July 2000, the Vietnam Stock Exchange has had a rapid growth in scale and volume of listed stocks, value of transactions. The numbers of accounts of individual investors in Vietnam market made up a large proportion of total transaction accounts. However, individual investors suffer from different feelings and are vulnerable easily. This fact made theory of finance unable to explain the behaviors of individual investors in the Vietnam Stock Exchange.

The Efficient Market Hypothesis (EMH) which relates to the traditional finance theory assumes that individual investors are fully rational and desire to maximize their expected utility. Their behaviors do not depend on emotions or psychology (Fama 1970, 1991). Although this theory succeeded in explaining market behaviors and was accepted widely (Fama achieved a Nobel Prize because of this theory), EMH could not satisfy economics, especially the scientists of behavioral finance.

Behavioral finance is a part of finance. It investigates and explains factors of human psychology and their effects on investment decision making in financial market. It also uses the special knowledge in Psychology, Sociology as well as Finance to explain uncommon behaviors of investors which cannot be understood fully by Traditional Finance. Behavioral finance evaluates people in the real world because individual investors are normal people who are affected by factors of psychology and emotions. It can be denied that investors make decisions rationally but also depend on factors of psychology (emotions and cognitition). As they have a good feeling, they will become overoptimistic while with a bad emtion, they tend to criticize, claim or become excessively pessimistic.

The researchers of behavioral finance point out that there are various factors of psychology and emotions which 
affect behaviors of investors. Five popular psychology factors are overconfidence, optimism, herd behavior, psychology of risk and pessimistic.

\section{Psychology Factors Affecting Behaviors of Individual Investors on Stock Market}

Overconfidence happens as people overestimate the reliability of their skills, knowledge and accuracy of their information, or over optimistic about the future and the ability of control the situations (Camerer \& Lovallo, 1999; Hirshleifer, 2001; Glaser \& Weber, 2007).

Overconfidence can be expressed in many different forms. Apart from miscalibration, many people do not actually think that their ability and understanding are only better than average effect. In addition, illusion of control makes people believe that they have the ability to control the situations better than what they can and they are overly optimistic about everything.

Miscalibration is a trend in which investors usually overestimate theirselves than what others evaluate. They tend to overestimate their knowledge and ignore the risks. Shiller (2000) suggests that people often think they know more than they can do. A study about miscalibration is conducted in a controlled environment while participants are required to contruct a confidence interval based on their knowledge. The result shows that some people fall on a narrow confidence interval, meaning that they are overconfidence. This result is in line with studies of Lichtenstein et al. (1982). Debondt (1998) provided the findings from 46 individual investors in which confidence interval is narrower than price fluctuations. Glaser et al. (2009) also suggested the similar results as they did research about professional investors and students. The study of Hilton (2001) about analysis of exchange rate and prediction of stock price again noted narrow confidence intervals.

Another determinant of overconfidence is better than average effect in which people rated themselves higher than average or have unrealistic views of themselves (Taylor \& Brown, 1988). Odean (1998) found that overconfident investors tend to believe that they are superior to others about the possibility of choosing the best stocks as well as the best time to join and exit the stock market. However, on average they often receive lower rates of return in comparison with the average return of the market. He also claimed that overconfident investors have lower level of expected utility than rational investors and hold a less diversified portfolio.

Nevertheless, Kyle and Wang (1997) believed that overconfident investors can earn higher expected returns or greater expected utility than rational investors as overconfidence play an important role in increasing the volumne of transactions. Kyle and Wang (1997), Hirshleifer and Luo (2001), and Wang (2001) pointed out that overconfident investors can exist in the stock market. The overconfidence can explain why an increase in stock prices for 3 to 12 months ago will continue to go up in the next period and a decrease in stock prices for 3 to 12 months ago will continue to go down (Daniel et al., 1998). Scheinkman and Xiong (2003) gave the evidence that overconfidence can explain the bubbles on financial markets. In a research of Barber and Odean (2001), the factor that represents the confidence is gender. They summarized that both male and female expressed excessive confidence but male was at the higher level. However, female investors can gain returns from individual stocks more than male (Briony \& Colman, 1997). Pulford and Colman (1997) indicated that men are more confident than women because women are usually work under social pressure that lead them lack of confidence in their lives.

People believe that they have the ability to control the situation better than what they can, meaning that investors can use psychology and emotions to control or at leat affect outcomes of investment. However, in fact, they cannot. Illusion of control leads investors to overprice stocks which are losing values in their portfolio, or it makes them unrealistic, or purchasing stocks because they predict that these stocks will be better in the future althought the future prices can change differently past ones.

Excessive Optimism reflects that everything is better than the analysis. Excessive optimisim origins from overconfidence and the belief that future events will be better than the actual.

Optimism can help people have positive emotions, but excessive optimism or unrealistic optimism can cost. If people can not reach their targeted results of investment, they can become frustrated, loss of self- esteem and prestige in society. More importantly, it can cause reluctance to pursure other goals in the future which they are able to achieve actually. In addition, time and money can be wasted if they pursue unrealistic goals.

A typical theoretical research done by Gervais et al. (2002) found that excessive optimism often causes positive impacts because it encourages managers to invest in. This effect is possive because awareness of risks usually affects firm value negatively. However, excessive optimism can causes negative impacts as it can lead companies or investors to accept to invest in projects which have negative NPV or assets which have high risks.

There is not a clear boundary between overconfidence and excessive optimism. Many studies show that too 
optimism is a form of overconfidence because illusion of control (people who over appreciate their ability to control a somewhat matter) is also regarded as the expression of overconfidence or excessive optimism.

Excessive Pessimistic is opposed to over optimistic. Pessimistic investors believe that the future events would be worse and more negatively.

Herd Behavior or herd mentality is the behavior of an investor who imitates the action of other investors or follows the movement of the market instead of relying on their own strategic information (Biekhchandani and Sharma, 2001). Researchers of school of behavioral finance indicate that individual investors should always control their emotions to avoid being influenced by the public. If it is an irrational transaction of a single investor (individual or corporate), it does not greatly affect the stock price on the market. We call these phenomenon noise traders. Only when irrational behavior is systematic, meaning that a group of investors with same irrational behaviors, the errors of pricing will exist and last for a long time. Barber et al. (2009) reported that investors trend to behave wrongly on or around the same time. These investors do not necessarily remove the others' actions. In that case, individual investors can not be considered as noise traders, they are regarded as a big organization which has large impact on stock market, causing stock prices do not reflect actual and rational values. Herd mentality is expressed in the perspective in which investors follows the behaviors of their peers and do not act contrastly to them whatever they have any information.

In the finance sector, risk is a controversial concept. However, most arguments believe that risk is unexpected result and associated with uncertainty. Traditional Finance relates to quantitative measures of risk such as variance, standard devidation, beta and this theory suggests that each people have a constant risk. But behavioral finance takes qualitative factors into consideration. Thus, risk can be observed both in emotion and cognition (Olsen, 2007, 2008). In addition, two major form of psychology, namely awareness of risk and seeking of risk can exist in an individual under different situations.

Although research on behavioral finance has been made my many different economists, we lack of such researches in Vietnam. Some researchers such as Ly (2010) studied about whether psychology factors exist on the stock market or not and their effects on investment decision making of individual investors. Therefore, this paper is to investigate the existence of psychology factors and their effects on investors' decisions.

\section{Methodology}

In this paper, studied subjects are individual investors in the Vietnam Stock Exchange, including both Hanoi Stock Exchange (HNX) and Hochiminh Stock Exchange (HOSE). We used Snow ball samples to take the data. Based on personal relationships, people who are firsly interviewd will continue to introduce others to partipate in the study. Then we can collect enough information and data to conduct the research. Intervieees are investors who have at least 6 months experience on the stock market and still invest in stocks in August and September 2013. To ensure the reliability of the study, author selected 400 samples for the analysis of multivariate statistics (Lee, 1992).

The questionnaire was designed to assess psychology factors and targets of investors on the stock market. The scale used for each group of questions for factors are 5 point Likert scale $(1=$ totally disagree and $5=$ strongly agree). In order to ensure ethical rules on the questionnaire, we did not ask respondents filled in theirs names. The survey was designed and delivered to individuals in their network. Then interviewees filled out the questionnaire and return it to the author. There were two forms of response: investors in Hanoi answered questionnaire in hard copies while in Hochiminh, email and online survey were used to examine.

The questions are designed in the study as follows.

\section{1) Overconfidence is expressed through the results from following questions:}

OV1- Based on your own skills, you feel confident to evaluate securities prices in your investment portfolio by yourself.

OV2- On the stock market, you are confident to select securities better than other investors.

OV3- You can totally control your investment on the stock market.

OV4- You feel confident in the understanding of the stock market.

\section{2) Excessive optimism is expressed through the results from following questions:}

OP1- Although Vn- Index is loosing its value, you will continue to increase in investment on the stock market in the next one year.

OP2- You believe that the Vietnam Stock Exchange is an attractive investment channel. Then, in the next 
period, you will continue to invest in stock market.

OP3- At this time, the stock price is relatively low, but you believe that the stock price will increase again in the next time.

OP4- If VN- Index decrease its value by $5 \%$ tomorrow, you believe that it will quickly recover in the next few days.

3) Herd behavior is expressed through the results from following questions:

HB1- When you need to make decision to buy/sell stocks in a short time, following most investors' behaviors is fast and certain method.

HB2- Information from relatives, friends and colleagues has high reliability.

HB3- Information about transactions of foreign investors

HB4- Recommendations of analysts, market researchers, stock brokers.

4) Psychology of risk is expressed through the results from following questions:

RI1- You are risk- lover investor

RI2- When stocks' prices are decreasing; you usually hold them longer to wait for increasing trend.

RI3- In the market, companies which have prestige or about which you know more will be ranked at the top of your choice.

RI4- In the market, companies which pay the stable dividend rate are your first priority.

5) Excessive pessimistic is expressed through the results from following questions:

PS1- There may be the rapid decline in the stock prices like in late 2008 when VN- Index fell below 300 points.

PS2- In the Vietnam Stock Exchange, most stocks are overvalued in comparion with their actual prices.

This study is to investigate the existence of psychology factors of investors and their effects on investment behaviors. Thus, we tested by using Cronbach Alpha for theoretical concepts (Saunders et al., 2007) and corrected item- total correlation (Hair et al., 2006). Since this is a new study, Cronbach Alpha coefficient should be taken at least equal to 0.6, the corrected item- total correlation equal to at least 0.3 (Bernstein, 1994). Because of uncertainty about the relationships between factors, we used exploratory factor analyses (EFA) to examine the underlying psychology determinants from the answers. The appropriate standards to use exploratory factor analyses include KMO coefficient at least 0.5 , p-value of Bartlett test lower than 0.05 , total variance explained at least 50\%, factor loading coefficients higher than 0.5(Hair et al., 2006). After that, we used Confirmatory Factor Analysis (CFA). The appropriate standards to use CFA are: Chi-square/df smaller than 3, CFI, GFI, IFI bigger than 0.9, RMSEA lower than 0.08 (Hair et al., 2006). Due to the investment variables which consist of longterm investment (over 2 years) and short- term investment (under 2 years), we used logistic regression to assess the impact between psychology factors and investment targets (Maddala, 1984).

\section{Empirical Results}

\subsection{The Existence of Psychology Factors on the Stock Market}

Our final results from 422 respondents show that independent variables are consistent internally and no factors have Cronbach Alpha less than 0.6 (herd behavior HB has the smallest coefficient with $\alpha=.667$ ), corrected itemtotal correlation of OP2, HB1 are less than 0.3 so that we exclude them. Exploratory factor analyses (EFA) to explore all observed variables reports that psychology factors exist as expected theory. In addition, our data confirms that using EFA is fitted with the model as KMO coefficient higher than $0.5(0.804)$, p-value of Bartlett test smaller than 0.05 , total variance explained higher than $50 \%(65.37 \%)$ and all factor loading coefficients higher than 0.5. Confirmatory Factor Analysis (CFA) confirms that the findings are totally suitable with: Chi-square $/ \mathrm{df}=2.962>3 ; \mathrm{p}$-value $=.000<.05 ; \mathrm{GFI}=.923 ; \mathrm{CFI}=.909 ; \mathrm{IFI}=.910 ; \mathrm{TLI}=.883 ; \mathrm{RMSEA}=.068$; $\mathrm{RMR}=.061$ (As can see from Table 1 and Figure 1). This provided the evidence that psychology factors exist in the Vietnam Stock Exchange. 
Table 1. Results of scale reliability test and exploratory factor analyses for observed

\begin{tabular}{|c|c|c|c|c|c|}
\hline $\begin{array}{l}\text { Observed } \\
\text { Variable }\end{array}$ & $\begin{array}{l}\text { Corrected Item-Total } \\
\text { Correlation }\end{array}$ & $\begin{array}{l}\text { Crobach } \\
\text { Alpha }\end{array}$ & $\begin{array}{l}\text { Factor loadings } \\
(\mathrm{EFA})\end{array}$ & $\begin{array}{l}\text { Mean reliability } \\
\text { statistics }\end{array}$ & $\begin{array}{l}\text { Factor loadings } \\
(\mathrm{CFA})\end{array}$ \\
\hline \multicolumn{6}{|c|}{ Overconfidence } \\
\hline OV1 & .608 & \multirow{4}{*}{.781} & .772 & \multirow{4}{*}{.782} & .709 \\
\hline OV2 & .585 & & 695 & & .697 \\
\hline OV3 & .559 & & .740 & & .646 \\
\hline OV4 & .595 & & .742 & & .698 \\
\hline \multicolumn{6}{|c|}{ Excessive optimism } \\
\hline OP1 & .539 & \multirow{3}{*}{.739} & .767 & \multirow{3}{*}{.741} & .659 \\
\hline $\mathrm{OP} 3$ & .567 & & .797 & & .691 \\
\hline $\mathrm{OP} 4$ & .587 & & .803 & & .744 \\
\hline \multicolumn{6}{|c|}{ Herd behavior } \\
\hline HB2 & .479 & \multirow{3}{*}{.667} & .784 & \multirow{3}{*}{.669} & .617 \\
\hline HB3 & .501 & & .774 & & .652 \\
\hline HB4 & .459 & & .681 & & .634 \\
\hline \multicolumn{6}{|c|}{ Psychology of Risk } \\
\hline RI1 & .530 & \multirow{4}{*}{.758} & .705 & \multirow{4}{*}{.761} & .579 \\
\hline RI2 & .515 & & .784 & & .524 \\
\hline RI3 & .545 & & 699 & & .702 \\
\hline RI4 & .638 & & .726 & & .839 \\
\hline \multicolumn{6}{|c|}{ Excessive pessimistic } \\
\hline PS1 & .639 & \multirow{2}{*}{.779} & .882 & \multirow{2}{*}{.794} & .697 \\
\hline PS2 & .639 & & .774 & & .916 \\
\hline EFA & \multicolumn{5}{|c|}{$\mathrm{KMO}=.804 ; p$-value $($ Bartlett $)=.000 ;$ Total Variance Explained $=65.37 \%$} \\
\hline CFA & \multicolumn{5}{|c|}{$\begin{array}{l}\text { Chi-square }=278.448 ; \mathrm{df}=94 ; \text { Chi-square } / \mathrm{df}=2.962 ; p \text {-value }=.000 ; \mathrm{GFI}=.923 ; \mathrm{CFI}=.909 ; \mathrm{IFI}=.910 ; \\
\mathrm{TLI}=.883 ; \mathrm{RMSEA}=.068 ; \mathrm{RMR}=.061\end{array}$} \\
\hline
\end{tabular}

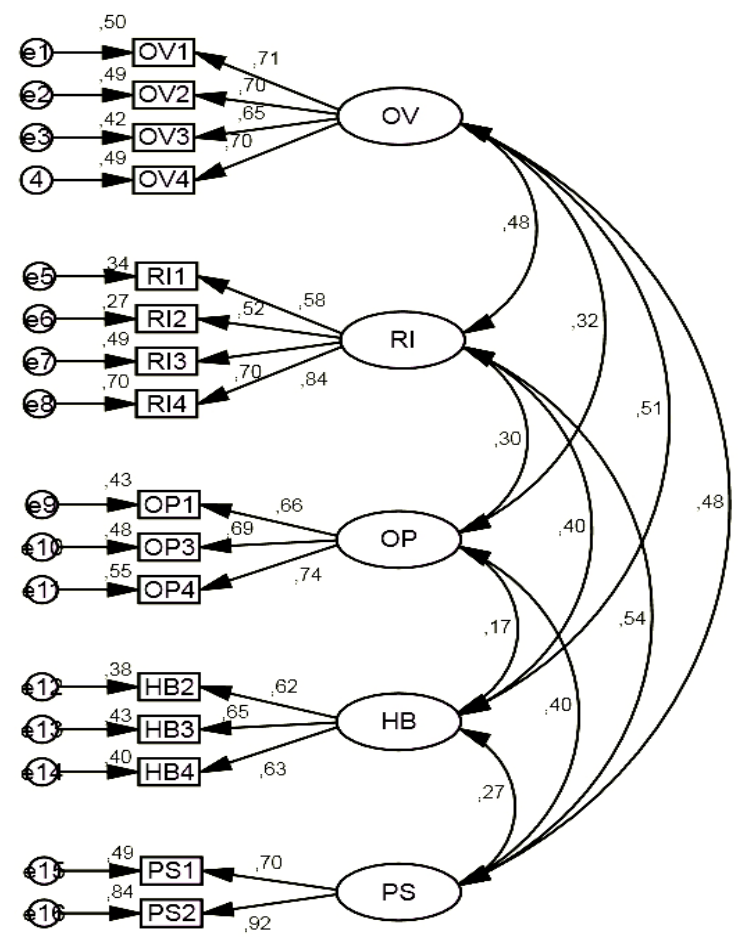

Figure 1. Results of CFA test for psychology factors 


\subsection{The Level of Investors' Assessment to Psychology Factors}

We used means of points investors evaluated and the value of standard devidation to assess the attitude of investors to psychology factors on the stock market. Results show that psychology of risk has the highest score $($ mean $=3.42, \mathrm{SD}=.74)$ and overconfidence has the lowest score $($ mean $=2.90, \mathrm{SD}=0.90) . \quad$ In general, the other scores are above average using a five point Likert scale (Table 2).

Table 2. Results of investors' assessment to psychology factors

\begin{tabular}{ccccc}
\hline Variable & \multirow{2}{*}{ Mean } & SD & Lower & Upper \\
\cline { 4 - 5 } & & .90824 & 2.8153 & 2.9892 \\
Overconfidence & 2.9023 & .81119 & 3.2770 & 3.4323 \\
Excessive optimism & 3.3547 & .82619 & 2.9999 & 3.1580 \\
Herd behavior & 3.0790 & .74481 & 3.3505 & 3.4931 \\
Psychology of Risk & 3.4218 & .98595 & 2.8713 & 3.0600 \\
Excessive pessimistic & 2.9656 &
\end{tabular}

To evaluate clearly the level of investors' assessment to psychology factors, we count the frequency of occurrence of each point (using a five point Likert scale) answered by interviees. Our findings as follows:

\section{- Overconfidence}

Table 2 reflects the results of confidence assement to individual investors. We can observe that as investors evaluated themselves, they expressed the attitude of overconfidence. The mean of overconfidence factor is $2.9023 / 5$ in which $70 \%$ (297 investors) feel confident to assess their portfolio over the average, only $30 \%$ (125 investors) are uncertain of their own decisions (OV1). When we assess the ability of selecting stocks compared to other investors, $65 \%$ (274 investors) believe that their decisions are better than others and the remaining of $35 \%$ (148 investors) insist that their decisions are worse (OV2). More than 54\% (229 investors) claim that they have the ability to control their investment (OV3). About understanding the stock market, $52 \%$ (221 investors) feel confident in understanding the Vietnam Stock Exchange and 48\% (201 investors) answer no (OV4). All the results conclude that individual investors on Vietnam stock market experience overconfidence.

\section{- Excessive optimism}

August and September 2013 carried out the survey is the time period when the Vietnam Stock Exchange faced with the most difficulties as stock prices continued to fall, the income of businesses were not satisfactory and the VN- Index decreased to 385 points. However, the survey shows that individual investors are excessive optimistic toward the stock market. Mean of excessive optimism is 3.3547/5, in which $75 \%$ (315 investors) believe that they will continue to invest in stock market at that time and only $25 \%$ (107 investors) answer that they are not willing to invest in (OP1). When assessing the expectations of investors, $67 \%$ (285 investors) insist that the stock prices will increase again in the next time while $33 \%$ (137 investors) see the opposite trend (OP3). As evaluating the recovery of market after VN- Index dropped by $5 \%, 76 \%$ (320 investors) believe in the ablity to recover in the next transaction and only $24 \%$ (102 investors) do not believe in that. In summary, in this period, investors optimize that the Vietnam Stock Exchange will jump out of the bottom and experience an upward trend.

\section{- Herd behavior of investors}

Our finding reports that mean of herd behavior factors is 3.079/5. 70\% (294 investors) answer they depend on information from relative, friends and colleagues deeply. In addition, $67 \%$ (285 investors) believe in the information from behaviors of foreign investors and 33\% do not believe in this information channel (HB3). About recommendations form analysts and market researchers, 76\% (321 investor) believe in their information while only $24 \%$ do not fully believe in them (HB4).

\section{- Psychology of risk}

The results express that the level of investors'assessment to psychology of risk gets the highest score $3.4218 / 5$ in which 75\% (316 investors) rank them as the risk- lover investors while $25 \%$ have the different point of view (RI1). Furthermore, 78\% (330 investors) will buy stocks when prices are declining to wait for increasing in the future (RI2). To companies which investors are familiar or have an understanding, $86 \%$ (362 investors) will invest in these companies and only 14\% (60 investors) invest in companies less knowledgable and less familiar (RI3). In addition, 84\% (355 investors) prefer firms which have a stable dividend payout policy while 16\% (67 investors) invest in other companies (RI4). 


\section{- Excessive pessimistic}

Besisdes excessive optimism, mean of excessive pessimistic factor is $3.42 / 5$. Thus, we can conclude that at this time, investors do not believe in an upward trend and there may be a decline in the stock prices in the market. $65 \%$ (273 investors) report that there could be a price shock like Vn- Index fell less than 300 points in 2008 and $35 \%$ answer that this shock will not happen (PS1). 52\% (220 investors) claim that Vietnam stock market is overvalued in comparison with its actual value whereas $48 \%$ (202 investors) do not think so. In genereal, the feeling of investors about the decline in the stock market is relatively high.

\subsection{The Effects of Psychology Factors on Individual Investors' Investment}

To evaluate the effects of psychology factors on the investment objectives of investors, we used Logistic Regression. The results illustrate that omnibus test has p-value smaller than 0.05 (.000), suggesting that there is at leat one factor affecting the investment objectives of investors. Wald test represents that all coefficients of the $\mathrm{OV}, \mathrm{HB}$ variables are not statistically significant at the $5 \%$ level (see Tables 3 and 4 ).

Table 3. Variables in the equation

\begin{tabular}{|c|c|c|c|c|c|c|c|}
\hline & & $\mathrm{B}$ & S.E. & Wald & $\mathrm{df}$ & Sig. & $\operatorname{Exp}(B)$ \\
\hline \multirow{8}{*}{ Step $1^{\mathrm{a}}$} & OV & .248 & .171 & 2.102 & 1 & .147 & 1.281 \\
\hline & OP & .329 & .173 & 3.634 & 1 & .049 & 1.420 \\
\hline & HB & .323 & .191 & 2.869 & 1 & .090 & 1.382 \\
\hline & RI & .640 & .191 & 11.296 & 1 & .001 & 1.897 \\
\hline & PS & .396 & .166 & 5.713 & 1 & .017 & 1.487 \\
\hline & Constant & -4.353 & .887 & 24.078 & 1 & .000 & .013 \\
\hline & \multicolumn{3}{|c|}{-2 Log likelihood } & \multicolumn{4}{|l|}{342.059} \\
\hline & \multicolumn{3}{|c|}{ Omnibus test } & \multicolumn{4}{|c|}{ Chi- square $=58.933 ; \mathrm{p}-$ value $=.000$} \\
\hline
\end{tabular}

a. Variable(s) entered on step 1: OV, OP, HB, RI, PS.

Table 4. Classification table ${ }^{\mathrm{a}}$

\begin{tabular}{|c|c|c|c|c|c|}
\hline \multirow{2}{*}{ Observed } & & & \multicolumn{3}{|c|}{ Predicted } \\
\hline & & & Short & Long & Percentage Correct \\
\hline \multirow{3}{*}{ Step 1} & \multirow{2}{*}{ Sta } & Short & 22 & 55 & 28.6 \\
\hline & & Long & 0 & 345 & 100.0 \\
\hline & \multicolumn{2}{|c|}{ Overall Percentage } & & & 87.0 \\
\hline
\end{tabular}

Notes: a. The cut value is .500

OV stands for overconfidence; OP stands for excessive optimism, HB stands for herd behavior; RI stands for psychology of risk; PS stands for excessive pessimistic

Our findings report that if we use this model to forecast the trend of investors'decision making, the probability is $87 \%$ accurate. The coefficients of OP, RI and PS are statistically significant (OP variable has the smallest p-value which is 0.049 less than 0.05 ). Thus, excessive optimism, psychology of risk and excessive pessimistic factors affect the investment's decision at the 5\% level statistically.The signs of coefficients are positive, indicating that optimism, psychology of risk and pessimistic increases the probability of choosing long- term investment and vice versa. Overconfidence and herd behavior factors have p-value higher than 0.05 (p-value of HB is .090 bigger than 0.05 ). Therefore, these two psychology factors do not affect the investors' decisions.

\section{Conclusions}

Our study shows the existence of psychology factors affecting investors' decision making in the Vietnam Stock Exchange. Five factors, namely overconfidence, optimism, herd behavior, psychology of risk and pessimistic also give evidence of their existence in Vietnamese investors. Our result is similar to previous research such as the study of Ly, T.T.H (2010) or a study on Asian stock market of Jonie \& Chien (2008).

The empirical findings suggest that only excessive optimism (OP), psychology of risk (RI) and excessive pessimistic (PS) affect investors' decision makings. This is in line with the study of Ly, T.T.H and Thao, H.T.P (2012) about Hochiminh Stock Exchange. Their research also indicates that psychology of risk and optimism 
factors have impact on the way investors invest in. However, our results do not show the influence of herd behavior clearly. This is contrast to some previous research on Vietnam stock market. Take for example, Ly, T.T.H and Thao, H.T.P (2012) propose that herd behavior is one of factors affecting investors' decisions. Despite such difference between two results, the difference is very small ( $\mathrm{p}$ - value of herd behavior is very small which is 0.09). This result may be bias by random factors in the real life. Similarly, overconfidence can have somewhat impacts on long-term investment. As a result, we should continue to conduct further research to test this hypothesis. Our findings also show that the market with its pressure on change have burden on long-term investors (investment is over a year). $80 \%$ investors tend to invest in long-term projects. This may be a sign that our economy is recovering and will grow better in the next period.

Psychology factors always exist in individuals naturally and can affect investors' behaviors. However, we can control these factors through information transparency or studies about psychology factors. Our research provides important results for investors to consider before each transaction. If investors have deep understanding about psychological behaviors which are not beneficial for them, they can limit or reduce its impact on their investment. Nevertheless, this only happens as research results are widely published and investors have a good understanding of behavioral finance.

Our results show that behavioral factors exist in individual investors commonly and affect investment strategies. But our study only focuses on the existence of these factors affecting the trend of investors' investment such as long-term or short- term. We do not mention about the benefits or drawbacks if theses factors are dominated. This is a new research path for other researchers to explain the behaviors of investors better as well as assess the negative impact of psychology factors to limit these behaviors.

Behavioral finance is a relatively new theory but is growing rapidly and useful and helpful for Traditional Finance. By connecting between psychological theory and practice of finance, behavioral finance has helped to explain difficult and sophisticate problems which can not be illustrated clearly by traditional economic theory and traditional finance theory.

\section{Acknowledgments}

This work was supported in part by grants from the Innovation Program of Shanghai Municipal Education Commission (No. 13ZS065), the Shanghai Philosophy and Social Science Planning Project (No. 2012BGL006), and the National Social Science Foundation of China (No. 13CGL057).

\section{References}

Barber, B., \& Odean, T. (2001). Boys will be boys: Gender, overconfidence, and common stock investment. The Quarterly Journal of Economics, 116(1), 261-292. http://dx.doi.org/10.1162/003355301556400

Barber, B., Odean, T., \& Zhu, N. (2009). Do retail trades move markets? The Review of Financial Studies, 22(1), 151-186. http://dx.doi.org/10.1093/rfs/hhn035

Barberis, N., \& Thaler, R. (2003). A survey of behavioral finance. In G. Constantinides, M. Harris, \& R. Stulz (Eds.), Handbook of the Economics of Finance. Amsterdam: North-Holland.

Bikhchandani, S., \& Sharma, S. (2000). Herd behavior in financial markets. IMF Staff Papers, 47(3), 279-310.

Briony, D. P., \& Colman, A. M. (1997). Overconfidence: Feedback and item difficulty effects. Personality and Individual Differences, 23(1), 125-133. http://dx.doi.org/10.1016/S0191-8869(97)00028-7

Camerer, C., \& Lovallo, D. (1999). Overconfidence and excess entry: An experimental approach. The American Economic Review, 89(1), 306-318. http://dx.doi.org/10.1257/aer.89.1.306

Comrey, A. L., \& Lee, H. B. (1992). A First Course in Factor Analysis. Hillsdale, NJ: Erlbaum.

De Bondt, W. F. M. (1998). A portrait of the individual investor. European Economic Review, 42, 831-844. http://dx.doi.org/10.1016/S0014-2921(98)00009-9

French, F. (1991). Efficient capital markets: II. The Journal of Finance, 46(5), 1575-1617. http://dx.doi.org/10.1111/j.1540-6261.1991.tb04636.x

French, K., \& Eugene, F. (1993). Common risk factors in the returns on stocks and bonds. Journal of Financial Economics, 33, 3-56. http://dx.doi.org/10.1016/0304-405X(93)90023-5

Gervais, S., Heaton, J. B., Odean, T., \& Rodney, L. W. C. (2002). The positive role of overconfidence and optimism in investment policy. Working Papers, Rodney L White Center for Financial Research.

Hair, J. F., Black, W. C., Babin, B. J., Anderson, R. E., \& Tatham, R. L. (2003). Multivariate Data Analysis. 
Upper Saddle River, NJ: Pearson Prentice Hall.

Hirshleifer \& Luo. (2001). On the survival of overconfident traders in a competitive securities market. Journal of Financial Markets, 4, 73-84. http://dx.doi.org/10.1016/S1386-4181(00)00014-8

Hirshleifer, D., \& Teoh, S. H. (2003). Herd behaviour and cascading in capital markets: A review and synthesis. European Financial Management, 9(1), 25-66. http://dx.doi.org/10.1111/1468-036X.00207

Kyle, A. S., \& Wang, F. A. (1997). Speculation duopoly with agreement to disagree: Can overcon-fidence survive the market test? The Journal of Finance, 52(5), 2073-2090. http://dx.doi.org/10.1111/j.1540-6261.1997.tb02751.x

Lichtenstein, S., Fischhoff, B., \& Phillips, L. D. (1982). Calibration of subjective probabilities: The state of the art up to 1980. In D. Kahneman, P. Slovic, \& A. Tversky (Eds.), Judgment under Uncertainty: Heuristics and Biases (pp. 306-334). New York: Cambridge University Press. http://dx.doi.org/10.1017/CBO9780511809477.023

Ly, T. T. H. (2010). Herd behavior in Vietnamese stock market: Causes and some solutions. Economic Development Review.

Ly, T. T. H., \& Thao, H. T. P. (2012). The influence of psychological factors on the objectives of investors in Vietnam's stock market. Development and integration Review.

Maddala, G. S. (1983). Limited Dependent and Qualitative Variables in Econometrics. Cambridge University Press. http://dx.doi.org/10.1017/CBO9780511810176

Maditinos, D. I., Sevic, Z., \& Theriou, N. G. (2007). Investors' behavior in the Athens Stock Exchange (ASE). Studies in Economics and Finance, 24(1), 32-50. http://dx.doi.org/10.1108/10867370710737373

Markus, G., \& Weber, M. (2007). Overconfidence and trading volume. Geneva Risk and Insurance Review, 32(1), 1-36. http://dx.doi.org/10.1007/s10713-007-0003-3

Markus, G., Langer, T., \& Weber, M. (2012). True overconfidence in interval estimates: Evidence based on a new measure of miscalibration. Journal of Behavioral Decision Making, 10, 405-417.

Nunnally, J. C., \& Bernstein, I. H. (1994). Psychometric Theory. New York: McGraw-Hill.

Odean, T. (1998). Are investors reluctant to realize their losses? The Journal of Finance, 53(5), 1775-1798. http://dx.doi.org/10.1111/0022-1082.00072

Olsen, R. A. (2007). Investors' Predisposition for annuities: A psychological perspective. Journal of Financial Service Professionals, 61(5), 51-57.

Olsen, R. A. (2008). Cognitive dissonance: The problem facing behavioral finance. Journal of Behavioral Finance, 9(1), 1-4. http://dx.doi.org/10.1080/15427560801896552

Pulford, B. D., \& Colman, A. M. (1997). Overconfidence: Feedback and item difficulty effects. Personality and Individual Differences, 23, 125-133. http://dx.doi.org/10.1016/S0191-8869(97)00028-7

Saunders, M., Lewis, P., \& Thornhill, A. (2009). Research Methods for Business Students. London: Prentice Hall.

Scheinkman, J. A., \& Xiong, W. (2003). Overconfidence and Speculative Bubbles. Journal of Political Economy, 111(6). http://dx.doi.org/10.1086/378531

Shiller, R. J. (2000). Irrational Exuberance. Princeton University Press.

Subrahmanyam, A., Hirshleifer, D., \& Daniel, K. D. (1998). Investor psychology and security market under- and overreactions. The Journal of Finance, 53(6), 1839-1885. http://dx.doi.org/10.1111/0022-1082.00077

Subrahmanyam, A., Hirshleifer, D., \& Daniel, K. D. (2001). Overconfidence, arbitrage, and equilibrium asset pricing. The Journal of Finance, 56(3), 921-965. http://dx.doi.org/10.1111/0022-1082.00350

Taylor \& Brown. (1998). Illusion and well-being: A social psychological perspective on mental health. Psychological Bulletin, 103(2), 193-210.

Thaler, R. H. (2005). Advances in Behavioral Finance. Princeton University Press.

Tversky, A., \& Kochler, D. J. (1994). Support theory: A nonextensional representation of subjective probability. Psychological Review, 101(4), 547-567. http://dx.doi.org/10.1037/0033-295X.101.4.547

Wang, A. (2001). Overconfidence, investor sentiment and evolution. Journal of Financial Intermediation, 10(2), 138-170. http://dx.doi.org/10.1006/jfin.2001.0311 


\section{Copyrights}

Copyright for this article is retained by the author(s), with first publication rights granted to the journal.

This is an open-access article distributed under the terms and conditions of the Creative Commons Attribution license (http://creativecommons.org/licenses/by/3.0/). 